Pecvnia, Monográfico (2009), pp. 243-261

\title{
El arrendamiento financiero y operativo
}

\author{
Yolanda Fernández Santos \\ yfers@unileon.es \\ Universidad de León
}

Fac. de Ciencias Económicas y Empresariales

Campus de Vegazana, $\mathrm{s} / \mathrm{n}$

24071 León (España)

\section{INTRODUCCIÓN}

En el marco internacional, las principales normas e interpretaciones emitidas por el International Accounting Standard Board (IASB) que desarrollan los arrendamientos son la NIC "17. Arrendamientos", SIC "15. Arrendamientos operativos - Incentivos" y la SIC "27. Evaluación del fondo económico de las transacciones que adoptan la forma legal de un arrendamiento".

En el ámbito nacional, el nuevo Plan General de Contabilidad (PGC), aprobado por Real Decreto 1514/2007, de 16 de noviembre y el PGC de Pymes aprobado por Real Decreto 1515/2007, de 16 de noviembre, introducen determinadas modificaciones en la consideración y tratamiento contable de los arrendamientos financieros y operativos con respecto al PGC de 1990. 
El nuevo PGC regula los arrendamientos en la Norma de Registro y Valoración (NRV) " 8 a . Arrendamientos y otras operaciones de naturaleza similar", y el PGC de Pymes en la NRV $9^{a}$ con la misma denominación.

En los mismos términos que la NIC 17, la norma del PGC y del PGC de Pymes definen arrendamiento como:

cualquier acuerdo, con independencia de su instrumentación jurídica, por el que el arrendador cede al arrendatario, a cambio de percibir una suma única de dinero o una serie de pagos o cuotas, el derecho a utilizar un activo durante un periodo de tiempo determinado, con independencia de que el arrendador quede obligado a prestar servicios en relación con la explotación o mantenimiento de dicho activo.

Ambos Planes Generales de Contabilidad hacen una clara diferencia entre arrendamiento financiero y operativo que condiciona tanto el tratamiento contable como la información a revelar en las Cuentas Anuales.

\section{LOS ARRENDAMIENTOS EN EL PGC DE 2007}

La norma de registro y valoración $8^{a}$ del PGC, que regula el arrendamiento financiero y operativo, está dividida en cuatro apartados: 1. Arrendamiento financiero; 2 . Arrendamiento operativo; 3. Venta con arrendamiento financiero posterior; y 4. Arrendamientos de terrenos y edificios. Del mismo modo, el primer apartado se subdivide en otros tres: 1.1. Concepto; 1.2. Contabilidad del arrendatario; y 1.3. Contabilidad del arrendador.

A continuación se pasa a analizar y comentar los puntos relevantes de esta norma con el objeto de facilitar al lector su estudio y aplicación.

\subsection{El arrendamiento financiero}

\subsubsection{Concepto}

De acuerdo con esta norma, el arrendamiento financiero se define como aquél contrato cuyas condiciones económicas permite deducir 
que se transfieren sustancialmente todos los riesgos y beneficios inherentes a la propiedad del activo objeto del contrato.

En este caso, la calificación de un contrato de arrendamiento financiero se basa en la transferencia sustancial de los riesgos y beneficios inherentes a la propiedad del activo, a diferencia del PGC de 1990 que radicaba en la existencia de una opción de compra sobre la que al inicio de contrato no había dudas de su ejercicio.

Por tanto, el PGC basa la calificación de arrendamiento financiero en el fondo económico del contrato más que en su forma jurídica. De esta forma, se amplía el número de operaciones que serán consideradas como arrendamiento financiero. Incluso, se especifica la posibilidad de que el arrendador y el arrendatario califiquen una misma operación de arrendamiento de forma diferente.

Los supuestos que establece el PGC para considerar que un arrendamiento se califique como financiero son:

a) En contratos de arrendamiento de un activo donde exista opción de compra: cuando no existan dudas razonables de que se va a ejercer dicha opción de compra.

Este supuesto plantea un problema de definición de las condiciones que suponen la no existencia de dudas razonables del ejercicio de la opción de compra al que da respuesta la Resolución del ICAC de 21 de enero de 1992 en su norma $8^{a} .4$ que establece: "Se entenderá que por las condiciones económicas del contrato no existen dudas razonables de que se va a ejercitar la opción de compra, entre otros, en los casos siguientes:

- Cuando, en el momento de firmar el contrato, el precio de la opción de compra sea menor que el valor residual que se estima tendrá el bien en la fecha en que se ejercite la opción de compra.

- Cuando el precio de la opción de compra en el momento de firmar el contrato sea insignificante o simbólico con relación al importe total del contrato de arrendamiento financiero."

b) En contratos de arrendamiento de un activo, aunque no exista opción de compra, se presume que se transfieren todos los riesgos y beneficios del activo cuando: 
- La propiedad de activo se transfiere, o de sus condiciones se deduzca que se va a transferir, al arrendatario al finalizar el plazo del arrendamiento.

- El período del arrendamiento ${ }^{1}$ coincida o cubra la mayor parte de la vida económica ${ }^{2}$ del activo, y siempre que de las condiciones pactadas se desprenda la racionalidad económica del mantenimiento de la cesión de uso.

- Al comienzo del arrendamiento, el valor actual de los pagos mínimos acordados por el arrendamiento suponga la práctica totalidad del valor razonable ${ }^{3}$ del activo arrendado.

- Las especiales características de los activos objeto del contrato de arrendamiento hacen que su utilidad quede restringida al arrendatario.

- El arrendatario puede cancelar el contrato de arrendamiento y las pérdidas sufridas por el arrendador a causa de tal cancelación fueran asumidas por el arrendatario.

- Los resultados derivados de las fluctuaciones en el valor razonable del importe residual recaen sobre el arrendatario.

- El arrendatario tiene la posibilidad de prorrogar el arrendamiento durante un segundo período, con unos pagos por arrendamiento que sean sustancialmente inferiores a los habituales del mercado.

Como puede apreciarse, se amplían con respecto a la normativa anterior el número de operaciones clasificadas como arrendamiento financiero, incluyendo no sólo los contratos de leasing donde no existan dudas sobre el ejercicio de la opción de compra, sino

1 El plazo de arrendamiento es el periodo no revocable para el cual el arrendatario ha contratado el arrendamiento del activo, junto con cualquier periodo adicional en el que éste tenga derecho a continuar con el arrendamiento, con o sin pago adicional, siempre que al inicio del arrendamiento se tenga la certeza razonable de que el arrendatario ejercitará tal opción.

2 La vida económica de un activo es el periodo durante el cual se espera que el activo sea utilizable por parte de uno o más usuarios o el número de unidades de producción que se espera obtener del activo por parte de uno o más usuarios.

3 El valor razonable es el importe por el que puede ser adquirido un activo o liquidado un pasivo, entre partes interesadas y debidamente informadas, que realicen una transacción en condiciones de independencia mutua. 
también contratos de renting ${ }^{4}$ cuando cumplen algunas de las circunstancias anteriormente enumeradas.

\subsubsection{Contabilidad del arrendatario}

Al inicio del arrendamiento financiero, el arrendatario que aplique el nuevo PGC debe reconocer un activo de acuerdo con su naturaleza, según se trate de un inmovilizado material o intangible, y un pasivo financiero por el mismo importe.

Este importe será el menor entre el valor razonable del bien arrendado y el valor actual al inicio del arrendamiento de los pagos mínimos acordados, entre los que se incluye el importe de la opción de compra cuando no existan dudas razonables sobre su ejercicio y cualquier importe que haya garantizado, directa o indirectamente. Además, los gastos inherentes a la operación en los que incurra el arrendatario deben considerarse como mayor valor del activo.

Por otra parte, se excluyen del valor inicial las cuotas de carácter contingente (pagos por arrendamiento cuyo importe no es fijo sino que dependen de la evolución futura de una variable) y el coste de los servicios e impuestos repercutibles por el arrendador, contabilizándose en las cuentas correspondientes y no como mayor valor del inmovilizado.

Para el cálculo del valor actual de los pagos se utiliza el tipo de interés implícito en el contrato de arrendamiento y si éste no se puede determinar, el tipo de interés del arrendatario para operaciones similares.

A los activos reconocidos en el balance derivados del arrendamiento financiero se les aplicará los criterios de amortización, deterioro y baja que correspondan según su naturaleza.

Por otra parte, los pasivos financieros que surjan como consecuencia del arrendamiento financiero se tendrán que valorar aplicando lo establecido en el apartado 3 de la NRV "9a. Instrumentos financieros" recogida en el nuevo PGC. Así, el valor inicial será el precio de la transacción, que equivale al valor razonable de la contraprestación

4 El renting se podría definir como un contrato de alquiler de bienes de equipo (mobiliario, automóviles, maquinaria, etc.) a medio y largo plazo por el cual el arrendatario se compromete a pagar una renta fija periódica -normalmente mensual o trimestral- durante el plazo de vigencia del contrato. A cambio de esta renta, recibirá de la compañía de Renting los siguientes servicios: a) uso del bien objeto de la operación; b) mantenimiento del bien; y, c) seguro del bien. 
recibida ajustado por los costes de transacción que les sean directamente atribuibles. Y su valoración posterior será a coste amortizado, que se define como el importe al que inicialmente fue valorado un pasivo financiero, menos los reembolsos de principal que se hubieran producido, más la parte imputada en la cuenta de pérdidas y ganancias, mediante la utilización del método del tipo de interés efectivo, de la diferencia entre el importe inicial y el valor de reembolso en el vencimiento.

Por tanto, la carga financiera total se distribuirá a lo largo del plazo del arrendamiento y se imputará a la cuenta de pérdidas y ganancias del ejercicio en que se devengue, aplicando el método del tipo de interés efectivo.

El tipo de interés efectivo es el tipo de actualización que iguala el valor en libros de un instrumento financiero con los flujos de efectivo estimados a lo largo de la vida esperada del instrumento, a partir de sus condiciones contractuales y sin considerar las pérdidas por riesgo de crédito futuras; en su cálculo se incluirán las comisiones financieras que se carguen por adelantado en la concesión de financiación.

sería:

Así, la formula para el cálculo del tipo de interés efectivo

$$
V_{\mathrm{O}}=\sum_{i=1}^{n} \frac{F E_{\mathrm{i}}}{(1+T I E)^{\mathrm{t}}}
$$

donde $V_{\mathrm{o}}$ es el valor en libros o, en su caso, el valor inicial del instrumento financiero, $F E_{\mathrm{i}}$ son los flujos de efectivo estimados a lo largo de la vida del instrumento, $t$ es el tiempo y TIE el tipo de interés efectivo a calcular.

\section{Ejemplo ${ }^{0}$ 1.- Arrendamiento financiero}

Una empresa suscribe a 1-10-X1 un contrato de arrendamiento financiero para la utilización de una maquinaria durante un plazo de 3 años. Los datos básicos del contrato son:

- El valor razonable de la máquina: 7.000€.

- Cuota postpagable anual: 2.500€ más el IVA correspondiente del 16\%.

- Opción de compra que se ejercitará al final del contrato (no incluida en los pagos anteriores): $500 €$.

- El tipo de interés implícito del contrato es del 6,76433\%.

- Vida útil estimada del bien: 10 años, sin valor residual al cabo de los mismos.

- El sistema de amortización aplicado es lineal en función de su vida útil. 
Se pide: Contabilizar las operaciones según el PGC.

\section{Solución.-}

El valor actual de los pagos mínimos que desembolsa la empresa utilizando el tipo de interés implícito del contrato es:

$$
V A=\frac{2.500,00}{(1+0,06764)^{1}}+\frac{2.500,00}{(1+0,06764)^{2}}+\frac{2.500,00+500,00}{(1+0,06764)^{3}}=7.000,00
$$

Este arrendamiento se califica como financiero al cumplir claramente dos de las premisas establecidas previamente para considerarlo como tal:

- La inexistencia de dudas razonables sobre el ejercicio de la opción de compra.

- La coincidencia entre el valor razonable del activo y el valor actual de los pagos futuros.

El cuadro de amortización del contrato de arrendamiento financiero es el siguiente:

\begin{tabular}{|c|c|c|c|c|c|c|}
\hline Fecha & $\begin{array}{c}\mathbf{( 1 )} \\
\text { Cuotas }\end{array}$ & $\begin{array}{c}(\mathbf{2}) \\
\text { Amortización } \\
\text { del Principal }\end{array}$ & $\begin{array}{c}\mathbf{( 3 )} \\
\text { Intereses }\end{array}$ & $\begin{array}{c}\mathbf{( 4 )} \\
\text { Deuda a coste } \\
\text { amortizado } \\
\mathbf{( 4 + 3 - 1 )}\end{array}$ & $\begin{array}{c}\mathbf{( 5 )} \\
\text { Capital } \\
\text { Pendiente }\end{array}$ & $\begin{array}{c}\text { Cálculo de los intereses } \\
\text { (TIE= 6,76433 \%) }\end{array}$ \\
\hline $1-10-\mathrm{X} 1$ & & & & 7.000 & 7.000 & \\
\hline $31-12-\mathrm{X} 1$ & & & 115,49 & $7.115,49$ & 7.000 & $7.000(1+0,0676)^{3 / 12}-7.000$ \\
\hline $1-10-\mathrm{X} 2$ & 2.500 & $2.026,50\left(^{*}\right)$ & 358,02 & $4.973,50$ & $4.973,50$ & $7.115,49(1+0,0676)^{9 / 12}-7.115,49$ \\
\hline $31-12-\mathrm{X} 2$ & & & 82,05 & $5.055,56$ & $4.973,50$ & $4.973,50(1+0,0676)^{3 / 12}-4.973,50$ \\
\hline $1-10-\mathrm{X} 3$ & 2.500 & $2.163,58$ & 254,37 & $2.809,93$ & $2.809,92$ & $5.055,56(1+0,0676)^{9 / 12}-5.055,56$ \\
\hline $31-12-\mathrm{X} 3$ & & & 46,36 & $2.856,29$ & $2.809,92$ & $2.809,93(1+0,0676)^{3 / 12}-2.809,93$ \\
\hline $1-10-\mathrm{X} 4$ & 2.500 & $2.309,92$ & 143,72 & 500 & 500 & $2.856,29(1+0,0676)^{9 / 12}-2.856,29$ \\
\hline $1-10-\mathrm{X} 4$ & 500 & 500 & & & 0 & \\
\hline Total & & $\mathbf{7 . 0 0 0 , 0 0}$ & $\mathbf{1 . 0 0 0 , 0 0}$ & & & \\
\hline
\end{tabular}

(*) Se calcula restando a la cuota el importe de los intereses devengados en cada uno de los años financieros $(\mathrm{Ej}$.: $2026,50=2.500-358,02-115,49$ ).

El tratamiento contable para el arrendatario es el siguiente:

A la firma del contrato de arrendamiento financiero a 1-10-X1:

\begin{tabular}{|c|c|c|c|c|}
\hline \multirow[t]{2}{*}{$7.000,00$} & \multirow[t]{2}{*}{213 Maquinaria } & a & $\begin{array}{l}524 \text { Acreedores por } \\
\text { arrendamiento financiero a CP }\end{array}$ & $2.026,50$ \\
\hline & & $\mathrm{a}$ & $\begin{array}{l}174 \text { Acreedores por } \\
\text { arrendamiento financiero a LP } \\
(2.163,58+2.309,93+500)\end{array}$ & $4.973,50$ \\
\hline
\end{tabular}

De acuerdo con la norma de registro y valoración "9a . Instrumentos financieros", la valoración posterior de la deuda se tiene que hacer a coste amortizado. Por tanto, a 31-12-X1 se contabiliza la imputación de los intereses devengados en dicho ejercicio a pérdidas y ganancias aplicando el tipo de interés efectivo (ver cuadro de amortización):
115,49662 Intereses de deudas \begin{tabular}{l}
524 Acreedores por arrendamiento \\
financiero a CP \\
\hline
\end{tabular}

Por la amortización del bien a 31-12-X1:

\begin{tabular}{cc}
700,00 & 681 Amortización del \\
Inmovilizado Material \\
$(7.000 / 10$ años $)$ \\
\hline
\end{tabular}

\section{a 281 Amortización Acumulada} del Inmovilizado Material 
Por la contabilización de los intereses devengados hasta el 1-10-X2 y valorar la deuda a coste amortizado:

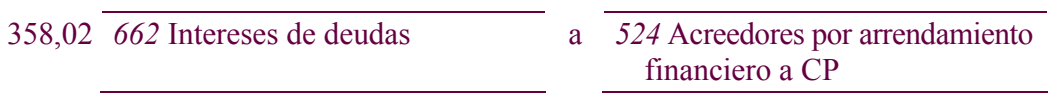

Por el pago de la cuota y el IVA correspondiente a 1-10-X2:

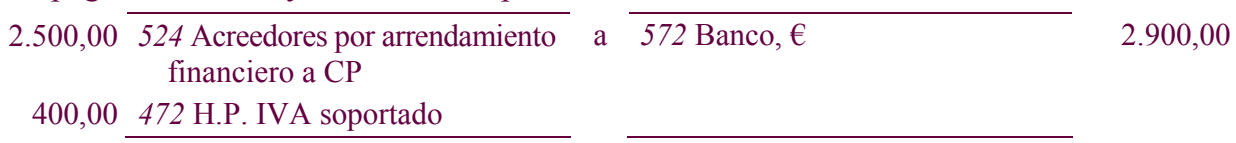

Por el traspaso de la deuda a largo plazo que es exigible a corto plazo a 1-10-X2:
$2.163,5 8 \longdiv { 1 7 4 \text { Acreedores por arrendamiento } }$ financiero a LP
a 524 Acreedores por arrendamiento financiero a $\mathrm{CP}$

Y así, sucesivamente, se procedería de la misma manera en el devengo de los intereses, pago de las cuotas, reclasificación de la deuda y amortización del elemento hasta llegar al 1-10$\mathrm{X} 4$, donde se ejerce la opción de compra:
$500,0 0 \longdiv { 5 2 4 \text { Acreedores por arrendamiento a } }$
financiero a $\mathrm{CP}$
572 Banco, $€$
580,00
$80,00 \quad 472$ H.P. IVA soportado

\subsubsection{Contabilidad del arrendador}

El arrendador, en el momento inicial, reconocerá un crédito por el valor actual de los pagos mínimos a recibir por el arrendamiento más el valor residual del activo, aunque no esté garantizado, descontados al tipo de interés implícito del contrato.

El arrendador reconocerá el resultado derivado de la operación de arrendamiento según lo dispuesto en el apartado 3 de la norma sobre inmovilizado material, salvo cuando sea el fabricante o distribuidor del bien arrendado, en cuyo caso se considerarán operaciones de tráfico comercial y se aplicarán los criterios contenidos en la norma relativa a ingresos por ventas y prestación de servicios.

La diferencia entre el crédito contabilizado en el activo del balance y la cantidad a cobrar, correspondiente a intereses no devengados, se imputará a la cuenta de pérdidas y ganancias del ejercicio en que dichos intereses se devenguen, de acuerdo con el método del tipo de interés efectivo.

Las correcciones de valor por deterioro y la baja de los créditos registrados como consecuencia del arrendamiento se tratarán 
aplicando los criterios de los apartados 2.1 .3 y 2.9 de la norma relativa a los instrumentos financieros.

En la mayoría de los casos, el arrendador en un contrato de arrendamiento financiero es una entidad financiera. La contabilidad de este tipo entidades está regulada por la normativa específica que establezca el Banco de España.

\subsection{El arrendamiento operativo}

La NRV $n^{\circ} 8$ del PGC define el arrendamiento operativo como el acuerdo mediante el cual el arrendador conviene con el arrendatario el derecho a usar un activo durante un período de tiempo determinado, a cambio de percibir un importe único o una serie de pagos o cuotas, sin que se trate de un arrendamiento de carácter financiero.

En el arrendamiento operativo no se traspasan los riesgos y beneficios del elemento arrendado, aunque sí sus beneficios económicos, por lo que el arrendador recibirá una cuota periódica como contrapestación. Por tanto, según se trate del arrendador o el arrendatario, serán considerados como ingresos o gastos del ejercicio en el que se devenguen, imputándose a la cuenta de pérdidas y ganancias.

El arrendador continuará presentando y valorando los activos cedidos en arrendamiento conforme a su naturaleza, incrementando su valor contable en el importe de los costes directos del contrato que le sean imputables, los cuales se reconocerán como gasto durante el plazo del contrato aplicando el mismo criterio utilizado para el reconocimiento de los ingresos del arrendamiento.

Por otro lado, cualquier cobro o pago que pudiera hacerse al contratar un derecho de arrendamiento calificado como operativo, se tratará como un cobro o pago anticipado por el arrendamiento que se imputará a resultados a lo largo del periodo de arrendamiento a medida que se cedan o reciban los beneficios económicos del activo arrendado.

Ejemplo n ${ }^{0}$ 2.- Arrendamiento operativo

Una sociedad firma el 1-1-X1 un contrato de arrendamiento operativo para poder utilizar una máquina durante tres años. Las cuotas mensuales del arrendamiento se pagan al inicio de cada mes, cuyo importe asciende a 2.000€ + IVA del 16\%. Los costes de instalación y montaje de la máquina ascienden a $720 €$. 
Se pide: Contabilizar las operaciones según el arrendador y el arrendatario.

\section{Solución.-}

\section{a) Contabilidad del arrendatario}

Por el pago de la primera cuota a 1-1-X1:

$$
\begin{array}{rlrl} 
& 621 \text { Arrendamientos y cánones } & & \text { a } \\
320,00 & 472 \text { H.P. IVA soportado } &
\end{array}
$$

El registro contable del pago de las siguientes cuotas será igual.

Por los costes de instalación y montaje a 1-1-X1 si son a cargo del arrendatario, de acuerdo con lo previsto en la NRV $3^{\text {a }}$ relativa a normas particulares sobre inmovilizado material, apartado h) que establece que "las inversiones realizadas por el arrendatario, que no sean separables del activo arrendado o cedido en uso, se contabilizarán como inmovilizado material cuando cumplan la definición de activo y se amortizarán en función de la duración del contrato de arrendamiento cuando ésta sea inferior a la vida económica del activo".

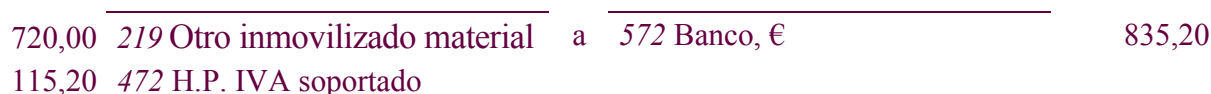

Por la amortización de los gastos de instalación y montaje activados a 31-12-X1:

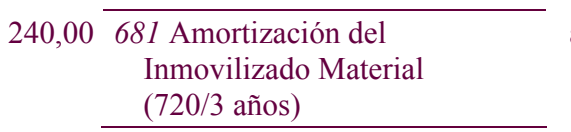

a 281 Amortización Acumulada del Inmovilizado Material

\section{b) Contabilidad del arrendador}

El arrendador tendrá contabilizada la maquinaria como inmovilizado material y se vendrá amortizando anualmente durante los años de su vida útil.

El registro del arrendamiento operativo inicialmente será por el cobro de la primera cuota a 1-1-X1:

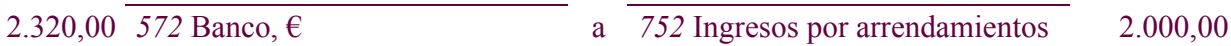

$$
\begin{aligned}
& \text { a } 477 \text { H.P. IVA repercutido } \quad 320,00
\end{aligned}
$$

El registro contable del cobro de las siguientes cuotas será igual.

Por los costes de instalación y montaje a 1-1-X1, si son a cargo del arrendador:

$\begin{array}{llll}720,00 & 2131 \text { Otra maquinaria } & \text { a } & 572 \text { Banco, } € \\ 115,20 & 472 \text { H.P. IVA soportado } & & \end{array}$

Estos costes de instalación y montaje se llevarán a otra cuenta distinta de la que recoge inicialmente la maquinaria arrendada, ya que el periodo de amortización de la maquinaria (vida útil) no va a coincidir con la duración del contrato, que es el periodo durante el cual deberán amortizarse estos gastos de instalación y montaje.

Por la amortización de los gastos de instalación y montaje activados a 31-12-X1: 


\begin{tabular}{cc}
\cline { 2 - 2 } 240,00 & 681 Amortización del \\
& Inmovilizado Material \\
$(720 / 3$ años $)$
\end{tabular}

281 Amortización Acumulada del Inmovilizado Material

\section{back o Retroleasing)}

\subsection{Venta con arrendamiento financiero posterior (Lease}

La venta con arrendamiento financiero posterior implica la enajenación de un activo y su posterior arrendamiento por parte del comprador al vendedor a lo largo de toda o parte de la vida económica del elemento. En este caso, el propietario inicial se convierte en arrendatario del mismo activo, por lo que el elemento no se mueve de la empresa. En esencia, el arrendatario pierde la propiedad legal, pero mantiene el control sobre todos o casi todos los beneficios económicos del activo a través del arrendamiento.

El objetivo de esta operación es obtener financiación de forma inmediata, pero manteniendo el uso del activo. Generalmente, el activo se enajena por un valor igual o superior a su valor razonable, y se vuelve a arrendar pagando unas cuotas cuyo importe será suficiente para reembolsar al arrendador el efectivo invertido más una rentabilidad establecida.

El arrendatario que haya vendido un activo conectado a un arrendamiento financiero posterior no variará la calificación del elemento, ni reconocerá beneficios ni pérdidas derivadas de la transacción. Adicionalmente, registrará el importe recibido con abono a una partida que ponga de manifiesto el correspondiente pasivo financiero.

La carga financiera total se distribuirá a lo largo del plazo del arrendamiento y se imputará a la cuenta de pérdidas y ganancias del ejercicio en que se devengue, aplicando el método del tipo de interés efectivo. Por otro lado, las cuotas de carácter contingente serán gastos del ejercicio en que se incurra en ellos.

\section{Ejemplo $n^{0}$ 3.- Venta con arrendamiento financiero posterior}

Una empresa posee una maquinaria que decide vender el 1-1-X1 con el objetivo de conectarla con posterioridad a una operación de arrendamiento financiero a fin de solventar sus problemas de liquidez. El precio de adquisición fue de $220.000 €$ y su amortización 
acumulada en el momento de realizar la operación es de 22.000€. La empresa utiliza el sistema de amortización lineal mediante la aplicación de un 10\% anual (IVA del 16\%).

La enajenación de la maquinaria se realiza por un importe de 200.000€, que coincide con su valor razonable (IVA del 16\%). El tipo de interés de la operación es del 8\%. La duración del contrato de arrendamiento financiero es de dos años, cuyas cuotas $(88.115,38 €)$ se pagan al final de cada ejercicio económico. La opción de compra asciende a $50.000 €$.

Se pide: Contabilizar estas operaciones según el Plan General de Contabilidad.

\section{Solución.-}

El cuadro de la operación financiera es el siguiente:

\begin{tabular}{|c|c|c|c|c|}
\hline Fecha & Cuotas & Intereses & $\begin{array}{c}\text { Amortización } \\
\text { del principal }\end{array}$ & $\begin{array}{c}\text { Capital } \\
\text { Pendiente }\end{array}$ \\
\hline $1-1-\mathrm{X} 1$ & & & & 200.000 \\
\hline $31-12-\mathrm{X} 1$ & $88.115,38$ & 16.000 & $72.115,38$ & $127.884,62$ \\
\hline $31-12-\mathrm{X} 2$ & $88.115,38$ & $10.230,76$ & $77.884,62$ & 50.000 \\
\hline $31-12-\mathrm{X} 2$ & 50.000 & & 50.000 & \\
\hline Total & $226.230,76$ & $26.230,76$ & 200.000 & \\
\hline
\end{tabular}

Por el registro del importe recibido y la deuda originada a 1-1-X1:

232.000,00 572 Banco, $€$ a

$$
\begin{gathered}
\text { a } \\
\cline { 2 - 2 } \text { a } \\
\text { financiero a CP } \\
\\
\\
\\
\text { financiero a LP } \\
(77.884,61+50.000)
\end{gathered}
$$

a 477 H.P. IVA repercutido $(16 \% \mathrm{~s} / 200.000)$
$72.115,38$

$127.884,62$

$32.000,00$

Las demás operaciones las registraremos como un arrendamiento financiero de acuerdo con las normas de registro y valoración establecidas en el PGC.

Por el pago de la primera cuota a 31-12-X1:

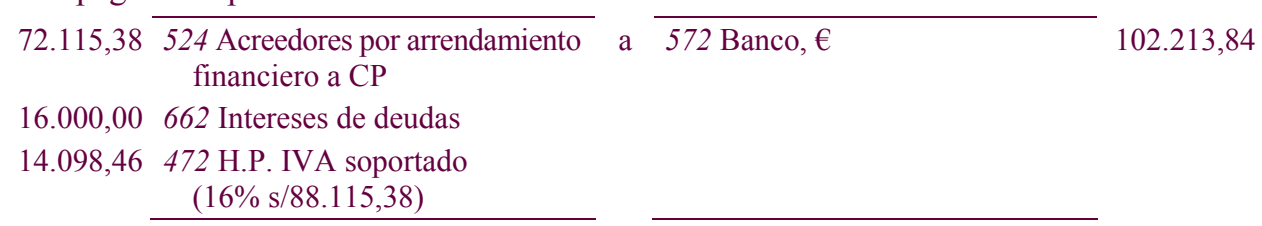

Por la amortización de la maquinaria a 31-12-X1:

\begin{tabular}{cc}
$22.000,00$ & $\begin{array}{c}\text { 681 Amortización del } \\
\text { Inmovilizado Material } \\
(10 \% \mathrm{~s} / 220.000)\end{array}$ \\
\hline
\end{tabular}

\section{Amortización Acumulada del Inmovilizado Material} $22.000,00$

La sociedad amortizará el bien como lo venía haciendo hasta ahora, ya que la operación es de carácter financiero y, por tanto, no afecta al tratamiento contable del activo objeto del contrato de lease back. 
Por la reclasificación de la deuda de largo a corto plazo a 31-12-X1:

$\begin{array}{ccccc}\text { 127.884,62 } & \begin{array}{l}\text { 174 Acreedores por arrendamiento } \\ \text { financiero a LP }\end{array} & \begin{array}{l}\text { 524 Acreedores por arrendamiento } \\ \text { financiero a CP }\end{array} & 127.884,62 \\ & (77.884,62+50.000) & & & \end{array}$

Así, se procede de la misma forma para la imputación de los intereses a la cuenta de pérdidas y ganancias, el registro del pago de la anualidad y la amortización del activo en el ejercicio X2.

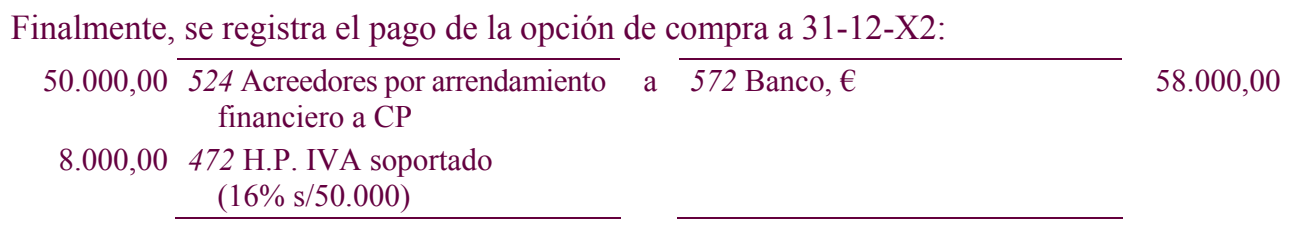

\subsection{Arrendamiento de terrenos y edificios}

Los arrendamientos conjuntos de terrenos y edificios se clasifican como operativos o financieros de la misma forma que los arrendamientos de otros activos.

Si embargo, dado que normalmente la vida económica de los terrenos es indefinida, en un arrendamiento financiero donde no se espera transferir la propiedad del inmueble al arrendatario al término del plazo del arrendamiento, los componentes de terreno y edificio se considerarán de forma separada, clasificándose el correspondiente al terreno como un arrendamiento operativo, salvo que se espere que el arrendatario adquiera la propiedad al final del periodo de arrendamiento.

En este sentido, los pagos mínimos por el arrendamiento se distribuirán entre el terrero y el edificio en proporción a los valores razonables relativos que representan los derechos de arrendamiento de ambos componentes, a menos que tal distribución no sea fiable, en cuyo caso todo el arrendamiento se clasificará como financiero, salvo que resulte evidente que es operativo.

Ejemplo $n^{\circ}$ 4.- Arrendamiento de terreno y edificio conjuntos

El 1-1-X1 una sociedad contrata un arrendamiento por una nave que necesita para almacén, cuyo valor razonable es de 153.724,51€, correspondiendo 30.744,90€ al terreno. El contrato se firma por un periodo de 30 años, al final de los cuales el bien retorna al arrendador. Las cuotas anuales que tiene que desembolsar el arrendatario al final de cada 
año son de 10.000€. El tipo de interés de la operación es del 5\%. La construcción tiene una vida económica de 30 años y se amortiza por el sistema lineal.

Se pide: Contabilizar estas operaciones según el PGC.

\section{Solución.-}

A pesar de que no existe opción de compra, esta operación se considera arrendamiento financiero porque:

(1) El valor actual de los pagos mínimos acordados por el arrendamiento es igual al valor razonable del activo arrendado.

$$
\begin{gathered}
V R=153.724,51 € \\
V A=\frac{1-(1+i)^{-n}}{i} \times r=\frac{1-(1+0,05)^{-30}}{0,05} \times 10.000=153.724,51
\end{gathered}
$$

(2) El plazo de arrendamiento (30 años) coincide con la vida económica del activo (30 años).

Por otra parte, dado que el terreno tiene una vida ilimitada se calculará la parte de la cuota que corresponde a la construcción y al terreno en función del porcentaje que representan en el valor inicial con el objeto de llevar el registro contable adecuado:

\begin{tabular}{|l|c|c|c|}
\hline \multicolumn{1}{|c|}{ Elemento } & VR & \% & Cuota \\
\hline Nave (total) & $153.724,51$ & 100 & 10.000 \\
\hline Terreno & $30.744,90$ & 20 & 2.000 \\
\hline Construcción & $122.979,61$ & 80 & 8.000 \\
\hline
\end{tabular}

Cuadro del cálculo del coste amortizado de la deuda originada por la construcción:

\begin{tabular}{|c|c|c|c|c|}
\hline Fecha & Cuota & $\begin{array}{c}\text { Intereses } \\
\mathbf{( 5 \% )}\end{array}$ & $\begin{array}{c}\text { Amortización } \\
\text { del principal }\end{array}$ & $\begin{array}{c}\text { Capital } \\
\text { pendiente }\end{array}$ \\
\hline $1-1-\mathrm{X} 1$ & & & & $122.979,61$ \\
\hline $31-12-\mathrm{X} 1$ & 8.000 & $6.148,98$ & $1.851,02$ & $121.128,59$ \\
\hline $31-12-\mathrm{X} 2$ & 8.000 & $6.056,43$ & $1.943,57$ & $119.185,02$ \\
\hline $31-12-\mathrm{X} 3$ & 8.000 & $5.959,25$ & $2.040,75$ & $117.144,27$ \\
\hline $31-12-\mathrm{X} 4$ & 8.000 & $5.857,21$ & $2.142,79$ & $115.001,48$ \\
\hline $31-12-\mathrm{X} 5$ & 8.000 & $5.750,07$ & $2.249,93$ & $112.751,56$ \\
\hline $31-12-\mathrm{X} 6$ & 8.000 & $5.637,58$ & $2.362,42$ & $110.389,14$ \\
\hline $31-12-\mathrm{X} 7$ & 8.000 & $5.519,46$ & $2.480,54$ & $107.908,59$ \\
\hline $31-12-\mathrm{X} 8$ & 8.000 & $5.395,43$ & $2.604,57$ & $105.304,02$ \\
\hline $31-12-\mathrm{X} 9$ & 8.000 & $5.265,20$ & $2.734,80$ & $102.569,22$ \\
\hline $31-12-\mathrm{X} 10$ & 8.000 & $5.128,46$ & $2.871,54$ & $99.697,68$ \\
\hline $31-12-\mathrm{X} 11$ & 8.000 & $4.984,88$ & $3.015,12$ & $96.682,57$ \\
\hline $31-12-\mathrm{X} 12$ & 8.000 & $4.834,13$ & $3.165,87$ & $93.516,70$ \\
\hline $31-12-\mathrm{X} 13$ & 8.000 & $4.675,83$ & $3.324,17$ & $90.192,53$ \\
\hline $31-12-\mathrm{X} 14$ & 8.000 & $4.509,63$ & $3.490,37$ & $86.702,16$ \\
\hline $31-12-\mathrm{X} 15$ & 8.000 & $4.335,11$ & $3.664,89$ & $83.037,27$ \\
\hline $31-12-X 16$ & 8.000 & $4.151,86$ & $3.848,14$ & $79.189,13$ \\
\hline $31-12-\mathrm{X} 17$ & 8.000 & $3.959,46$ & $4.040,54$ & $75.148,58$ \\
\hline $31-12-X 18$ & 8.000 & $3.757,43$ & $4.242,57$ & $70.906,01$ \\
\hline $31-12-X 19$ & 8.000 & $3.545,30$ & $4.454,70$ & $66.451,31$ \\
\hline $31-12-\mathrm{X} 20$ & 8.000 & $3.322,57$ & $4.677,43$ & $61.773,88$ \\
\hline
\end{tabular}




\begin{tabular}{|c|c|c|c|c|}
\hline $31-12-\mathrm{X} 21$ & 8.000 & $3.088,69$ & $4.911,31$ & $56.862,57$ \\
\hline $31-12-\mathrm{X} 22$ & 8.000 & $2.843,13$ & $5.156,87$ & $51.705,70$ \\
\hline $31-12-\mathrm{X} 23$ & 8.000 & $2.585,29$ & $5.414,71$ & $46.290,99$ \\
\hline $31-12-\mathrm{X} 24$ & 8.000 & $2.314,55$ & $5.685,45$ & $40.605,54$ \\
\hline $31-12-\mathrm{X} 25$ & 8.000 & $2.030,28$ & $5.969,72$ & $34.635,81$ \\
\hline $31-12-\mathrm{X} 26$ & 8.000 & $1.731,79$ & $6.268,21$ & $28.367,60$ \\
\hline $31-12-\mathrm{X} 27$ & 8.000 & $1.418,38$ & $6.581,62$ & $21.785,98$ \\
\hline $31-12-\mathrm{X} 28$ & 8.000 & $1.089,30$ & $6.910,70$ & $14.875,28$ \\
\hline $31-12-\mathrm{X} 29$ & 8.000 & 743,76 & $7.256,24$ & $7.619,05$ \\
\hline $31-12-\mathrm{X} 30$ & 8.000 & 380,95 & $7.619,05$ & \\
\hline Total & $\mathbf{2 4 0 . 0 0 0}$ & $\mathbf{1 1 7 . 0 2 0 , 3 9}$ & $\mathbf{1 2 2 . 9 7 9 , 6 1}$ & \\
\hline
\end{tabular}

Por la formalización del contrato y el registro de la construcción como arrendamiento financiero a 1-1-X1:

122.979,61 211 Construcciones a 524 Acreedores por arrendamiento financiero a $\mathrm{CP}$

a 174 Acreedores por arrendamiento financiero a LP (122.979,61-1.851,02)

Por el pago de la cuota a 31-12-X1:

6.148,98 662 Intereses de deudas

$1.280,00 \quad 472$ H.P. IVA soportado $(16 \% \mathrm{~s} / 8.000)$

A 31-12-X1 se contabiliza el pago de la parte de la cuota que corresponde al terreno como un arrendamiento operativo y, por tanto, será un gasto del ejercicio, sin que figure entre los activos de la sociedad el valor del mismo:

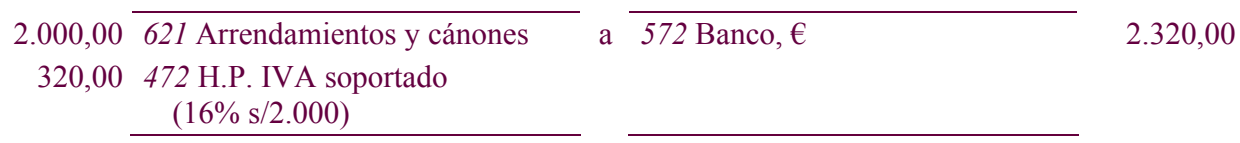

Por la amortización de la construcción a 31-12-X1:

$\begin{array}{ccccc}4.099,32 & \begin{array}{l}681 \text { Amortización del Inmovilizado } \\ \text { Material (construcción) }\end{array} & & \begin{array}{c}\text { 281 Amortización Acumulada del } \\ \text { Inmovilizado Material }\end{array} & 4.099,32 \\ & (122.979,61 / 30) & & \end{array}$

Por el traspaso de la deuda de largo a corto plazo a 31-12-X1:

\begin{tabular}{cccc}
$1.943,57$ & $\begin{array}{l}174 \text { Acreedores por arrendamiento } \\
\text { financiero a LP }\end{array}$ & $\begin{array}{l}524 \text { Acreedores por arrendamiento } \\
\text { financiero a CP }\end{array}$ \\
\hline
\end{tabular}

Así sucesivamente se procederá al final de cada año hasta llegar al término del contrato. 


\section{LOS ARRENDAMIENTOS EN EL PGC DE PYMES}

El PGC de Pymes regula los arrendamientos en la NRV "7a. Arrendamientos y otras operaciones de naturaleza similar", presentando los mismos apartados que la NRV $8^{\mathrm{a}}$ del PGC.

Esta norma, al igual que el PGC, establece los criterios para el tratamiento contable tanto del arrendamiento financiero como operativo, así como la venta con arrendamiento financiero posterior y arrendamiento de terreno y edificios.

La diferencia que existe entre la norma del PGC de Pymes y la establecida en el nuevo PGC respecto al arrendamiento financiero es la valoración inicial que debe realizar el arrendatario. Por tanto, éste contabilizará obligatoriamente el elemento arrendado y el pasivo financiero por el valor razonable del activo objeto del contrato de arrendamiento calculado al inicio del mismo. En consecuencia, como se puede apreciar, no se tiene en cuenta el valor actual de los pagos futuros que debe realizar el arrendatario para elegir el menor entre los dos valores como sucede en el nuevo PGC.

4. TRATAMIENTO CONTABLE DEL ARRENDATARIO SEGÚN LOS

\section{CRITERIOS ESTABLECIDOS PARA MICROEMPRESAS}

Los criterios contables establecidos para la contabilización de arrendamientos financieros para microempresas se recogen en el artículo 4 del Real Decreto 1515/2007, de 16 de noviembre, por el que se aprueba el PGC de Pymes, estableciendo diferencias entre arrendamientos financieros: (1) que tengan por objeto terrenos, solares u otros activos no amortizables; y (2) aquéllos otros que correspondan a activos que sí sean amortizables.

En el primer caso, se aplicarán los criterios de registro y valoración relativos a los arrendamientos financieros y otras operaciones de naturaleza similar contenidos en el PGC de Pymes.

En el segundo caso, arrendamientos financieros que no tengan por objeto terrenos, solares u otros activos no amortizables, las cuotas se contabilizarán como gasto en la cuenta de pérdidas y ganancias, concretamente el PGC de Pymes propone la "6211. Arrendamientos financiero y otros". Y cuando llegue la fecha de ejercer la opción de compra 
se registrará el activo por el precio de adquisición de dicha opción de compra.

Para la calificación de un arrendamiento como financiero u operativo se aplicarán lo dispuesto en la norma de registro y valoración $7^{a}$ incluida en la segunda parte del PGC de Pymes.

Por otro lado, las empresas que apliquen los criterios establecidos para microempresas en el tratamiento contable del arrendamiento financiero deberán indicar en el apartado "5. Inmovilizado material, intangible o inversiones inmobiliarias" de la memoria la siguiente información:

- Valor razonable o valor al contado del activo calculado al inicio del arrendamiento;

- Su vida útil estimada;

- Las cuotas abonadas;

- La deuda pendiente de pago;

- Y el importe por el que se pudiese ejercer la opción de compra, si la hubiere;

- La información acerca de las cuotas deberá suministrarse diferenciando la parte que corresponda a la recuperación del coste del bien y la carga financiera.

\section{Ejemplo $n^{0}$ 5.- Arrendamiento financiero según los criterios establecidos para microempresas}

Una sociedad suscribe a 1-1-X1 un contrato de arrendamiento financiero para la utilización de una maquinaria durante un plazo de 3 años. Los datos básicos del contrato son:

- Valor razonable de la máquina: $7.000 €$.

- Cuota postpagable anual: 2.500€ más el IVA correspondiente del 16\%.

- Opción de compra que se ejercitará al final del contrato (no incluida en los pagos anteriores): $500 €$.

- El tipo de interés implícito del contrato es del 6,76433\%.

- Vida útil estimada del bien: 10 años, sin valor residual al cabo de los mismos.

- El sistema de amortización aplicado es el lineal en función de su vida útil.

Se pide: Contabilizar las operaciones según los criterios establecidos para microempresas.

Solución.-

Por el pago de la cuota de arrendamiento a 31-12-X1: 


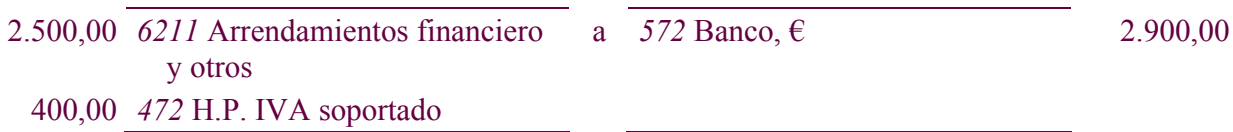

De igual forma procedería la misma anotación contable hasta llegar a la contabilización de la opción de compra a 31-12-X3, la cual se contabiliza como el precio de adquisición del activo:
500,00213 Maquinaria
572 Banco, $€$
580,00
80,00472 H.P. IVA soportado

Por el registro de la amortización de la maquinaria a 31-12-X4 en función de la vida útil restante.

Vida útil restante $=$ vida útil al inicio del arrendamiento - vida útil transcurrida hasta la fecha en la que se ejercita la opción de compra $=10$ años -3 años $=7$ años:

\begin{tabular}{cccc}
71,43 & $\begin{array}{l}\text { 681 Amortización del } \\
\text { Inmovilizado Material } \\
(500 / 7 \text { años })\end{array}$ & $\begin{array}{c}\text { 281 Amortización Acumulada } \\
\text { del Inmovilizado Material }\end{array}$ & 71,43 \\
\hline
\end{tabular}

El resto de los años hasta completar la vida útil restante se procederá a contabilizar la amortización con idéntico criterio.

\section{BIBLIOGRAFÍA}

INTERNATIONAL ACCOUNTING STANDARDS BOARD (2006) Norma Internacionales de Información Financiera (NIIF), texto completo de las normas internacionales de información financiera emitidas a 1 de enero de 2006, traducción al español publicada por CISS-PRASIS con la autorización de la IASCF.

LEY 16/2007, de 4 de julio, de reforma y adaptación de la legislación mercantil en materia contable para su armonización internacional con base en la normativa de la Unión Europea (BOE n ${ }^{\circ}$ 160, de 5 de julio).

LEY 37/1992, de 28 de diciembre, del Impuesto sobre el Valor Añadido (BOE $\mathrm{n}^{\circ} 312$, de 29 de diciembre).

REAL DECRETO 1514/2007, de 16 de noviembre por el que se aprueba el Plan General de Contabilidad.

REAL DeCRETO 1515/2007, de 16 de noviembre por el que se aprueba el Plan General de Contabilidad de Pequeñas y Medianas Empresas y los criterios contables específicos para microempresas. 
RESOLUCIÓN DEL ICAC de 21 de enero de 1992 del Instituto de Contabilidad y Auditoría de Cuentas por la que se dictan normas de valoración del inmovilizado inmaterial.

ZAMORA RAMíREZ, C. (Coord.) (2008) Análisis práctico y guía de implantación del nuevo PGC. Valencia: Ediciones contables, CISS. 